\title{
Remembering chosen and assigned options
}

\author{
MARA MATHER \\ University of California, Santa Cruz, California \\ ELDAR SHAFIR \\ Princeton University, Princeton, New Jersey \\ and \\ MARCIA K. JOHNSON \\ Yale University, New Haven, Connecticut
}

\begin{abstract}
Recent studies have shown systematic choice-supportive memory for past choices, wherein people tend to overattribute positive features to options they chose and negative features to unchosen options (Mather \& Johnson, 2000; Mather, Shafir, \& Johnson, 2000). In contrast, the present experiments showed no choice-supportive memory bias for assigned options. Rather than having a general motivation to recall the chosen or the assigned option in a more positive light, people appear to be influenced by heuristics that vary with context: In recalling past choices, people expect the chosen option to contain more positive and fewer negative features than do its competitors. In recalling past assignments, in contrast, people expect the assigned option to be remembered better than the unassigned alternatives. This vividness heuristic leads to systematic misattribution of new features to unassigned alternatives, but not in a manner supportive of the assigned option. Some implications of these findings are discussed.
\end{abstract}

Recent studies have shown systematic patterns of memory distortion in people's recall of past choices (Mather \& Johnson, 2000; Mather, Shafir, \& Johnson, 2000). Participants who had chosen between job candidates, for example, were then asked to make source attributions regarding the candidates' features (e.g., was the easily discouraged feature associated with the first job candidate, the second job candidate, or neither?). Participants attributed a greater number of positive features to the options they had chosen and a greater number of negative features to the unchosen options. Such choice-supportive memory distortion is an example of the types of errors that result from the imperfect encoding, retrieval, and evaluation processes that underlie human memory (e.g., Johnson \& Raye, 1981, 2000; Roediger, 1996; Schacter, 1999).

The source-monitoring framework (e.g., Johnson, Hashtroudi, \& Lindsay, 1993; Johnson \& Raye, 2000; Mitchell \& Johnson, 2000) summarizes various mechanisms by which such memory distortions arise. A number of these are related to the fact that remembering is the product not only of the features that might be active at any given time, but also of people's expectations about what memories from various sources should be like. Perceived events, for example, tend to yield memories that are more perceptually rich than do events that are imagined (Johnson, Foley, Suengas, \& Raye, 1988; Mather, Henkel, \&

This work was supported by National Science Foundation Grant 0112284 and National Institute of Aging Grant AG09253. Correspondence concerning this article should be addressed to M. Mather, Psychology Department, Social Sciences 2, University of California, Santa Cruz, CA 95064 (e-mail: mather@ cats.ucsc.edu).
Johnson, 1997; Norman \& Schacter, 1997; Suengas \& Johnson, 1988). People capitalize on such regularities when attributing specific qualities to particular sources. This strategy need not be consciously accessible but can be inferred from people's memory attributions. If memories with certain qualities tend to be attributed (or misattributed) to one source rather than to another, this suggests that the source is perceived to be associated more with those qualities than are alternative potential sources.

The expectations that influence remembering consist not only of beliefs and implicit theories about the characteristics of episodic memories, such as perceptual and contextual detail, but also of knowledge, beliefs, and implicit theories about what people (including oneself) are like, how memory works, and so forth (Bayen, Nakamura, Dupuis, \& Yang, 2000; Johnson \& Raye, 2000; Johnson, Raye, Foley, \& Foley, 1981; Mather, Johnson, \& De Leonardis, 1999; Ross, 1989; Sherman \& Bessenoff, 1999; Spaniol \& Bayen, 2002). For example, in the case of choice-supportive memory, people are likely to assume that the chosen option contains the majority of attractive features - that is, that they chose the better of the available options. Along these lines, the very act of making a decision may lead people to evaluate pieces of information related to their chosen course of action more favorably (Holyoak \& Simon, 1999; Simon, Pham, Le, \& Holyoak, 2001).

Along with knowledge and belief, wishes and desires can also affect what information is retrieved and how it is evaluated when one is remembering (e.g., Johnson \& Raye, 2000; Johnson \& Sherman, 1990; Kunda, 1990). Choice-supportive memory may thus stem from inferences about one's own choices (namely, I chose the option 
with the good features) or from a desire to think of the option in one's possession as attractive (namely, what's mine is good). In either case, memory distortion is likely to promote a sense of satisfaction with the chosen options.

Of course, an individual is not always in control of which options are received. People often end up with options that were not chosen but, instead, were assigned by others, such as job assignments made by bosses, course instructors assigned by a registrar, or vacation spots selected by other family members. The way in which assigned options are remembered, especially as compared with options that could have been had instead, may affect people's eventual sense of satisfaction. Are systematic memory distortions exhibited in assignment situations as they are in choice situations?

If choice-supportive biases in the recollection of choices stem from a general motivation to believe that the option in one's possession is superior, people should show similar bias whether the option was chosen or assigned. In line with choice studies, people ought to be more likely to attribute positive features to the option they were assigned than to the unassigned alternative, and vice versa for negative features. On the other hand, if choice-supportive biases arise from inferences people make about their own choices, memories for decisions made by others may not yield such distortion.

In Experiment 1, we explored whether memory-based attribution of features to assigned and to unassigned options is influenced by feature valence, reminiscent of the pattern previously observed in the context of choice. To foreshadow our findings, it appears that unlike memory for chosen options, which is influenced by beliefs about option quality, memory for assigned options is influenced by beliefs about memory quality. Put differently, when they make a choice, people expect the selected option to have been more attractive, whereas when they are assigned an option, they expect the assigned option to be better remembered. Experiment 2 confirmed this difference in a direct comparison of memory for chosen and for assigned options, and in Experiment 3, we further explored the implications of source attribution in the context of assignment. Some final remarks conclude the paper.

\section{EXPERIMENT 1}

Participants were presented with hypothetical binarychoice scenarios, each on a separate page of a booklet. After studying the scenarios, they were asked to imagine that they had been assigned one of the two options. After a delay, the participants were given a source attribution test for the option features.

\section{Method}

\section{Participants}

One hundred and forty-one undergraduate volunteers were presented with two scenarios each. About half of the participants were presented with positive scenarios, involving relatively attractive options, and the other half were presented with negative scenarios, involving relatively unattractive options. Twenty participants who could not subsequently remember which option was assigned and 5 who failed to answer all the questions were excluded from further analysis, leaving 65 randomly assigned to the negative versions and 51 to the positive versions.

\section{Materials and Procedures}

One scenario involving a choice between dorm rooms and another a choice between lab partners appeared on the same page, in either a positive or a negative version. For the dorm room scenario, valence was manipulated by a set of filler features (not included in the memory test), which was either positive or negative. For the lab partner scenario, valence was manipulated via the instructions, which invited people to choose between "two people you like and might have selected yourself" or between "two people you dislike and would not have selected otherwise." The participants saw either the positive or the negative versions of both scenarios (reproduced in the Appendix).

The participants first rated, on a scale of 1 to 3 , how typical each option seemed of dorm rooms or of students at their college. For each scenario, they were then asked to imagine they had been assigned one of the two options (order counterbalanced) and were asked to rate, on a scale of 1 to 7 , how they thought they would like living in the assigned room or working with the assigned student. They were instructed not to return to previous sections of the booklet and were proctored. Following a 5-min unrelated questionnaire, the participants were given an 18 -feature source identification test for each scenario (which involved 6 old positive, 6 old negative, and 6 new features, and was identical for all the participants). For each feature tested, the participants had to attribute it (i.e., identify it as having belonged) to one of the options or to label it as new. As a manipulation check, upon completion of the memory test, the participants identified their assigned option.

\section{Results}

The two scenarios generated similar results, and the data were collapsed for purposes of analysis.

\section{Old-New Recognition}

We used $A^{\prime}$ scores (Macmillan \& Creelman, 1991) to gauge the participants' ability to discriminate previously presented features from new features. A 2 (version: positive options or negative options) $\times 2$ (feature valence: positive or negative) $\times 2$ (source: assigned or unassigned) analysis of variance (ANOVA) revealed better recognition memory for features belonging to assigned options $(M=$ $.79, S E=.01)$ than for those belonging to unassigned options $\left[M=.77, S E=.01 ; F(1,114)=11.15, M S_{\mathrm{e}}=0.00\right.$, $p<.01]$. The participants also had better old-new recognition memory for negative features $(M=.50, S E=.03)$ than for positive features $[M=.39, S E=.03 ; F(1,114)=$ $\left.20.13, M S_{\mathrm{e}}=0.01, p<.001\right]$, replicating findings of better memory for negative features in Mather et al. (2000). The lack of an interaction between version and feature valence indicated that there was better memory for negative features regardless of the perceived attractiveness of the options.

\section{Source Attribution Accuracy for Assigned Versus Unassigned Options}

We conducted the same ANOVA as above, this time using, as the dependent variable, the proportion of correctly recognized features that were correctly attributed (features were correctly recognized if they had been part 
of the original decision scenario no matter how they were attributed). The participants were more likely to correctly attribute features to assigned options $(M=.84, S E=.02)$ than to unassigned options $(M=.73, S E=.02)$, as was revealed by a main effect of source $[F(1,113)=26.44$, $\left.M S_{\mathrm{e}}=0.05, p<.001\right]$. In addition, assignments were more accurate for negative features $(M=.81, S E=.02)$ than for positive features $[M=.76, S E=.02 ; F(1,113)=$ $\left.8.17, M S_{\mathrm{e}}=0.05, p<.01\right]$. Because the proportion of recognized features misattributed to an option is dependent on the proportion that was correctly attributed to its alternative, this analysis also reveals greater misattributions to unassigned options than to assigned options. There were no other significant effects.

\section{Attributions to Assigned Versus \\ Unassigned Options}

A possible contributor to the greater source accuracy of recognized features for assigned options than for unassigned options might be a general propensity to attribute more features to assigned options. To examine this possibility, we compared the proportion of all old features (not just those correctly recognized) and the proportion of all new features attributed to assigned and to unassigned options, using a 2 (item type: old or new) $\times 2$ (attribution: assigned or unassigned) $\times 2$ (feature valence: positive or negative) $\times 2$ (version: positive options or negative options) ANOVA. ${ }^{1}$ There was a significant interaction of item type and attribution $\left[F(1,114)=39.49, M S_{\mathrm{e}}=0.03\right.$, $p<.001]$. As is shown in Figure 1, the participants were more likely to attribute old features to assigned options $(M=.46, S E=.01)$ than to unassigned options $(M=.34$, $S E=.01$; although $50 \%$ of the old features had been associated with each option) but were more likely to attribute new features to unassigned options $(M=.22, S E=.02)$ than to assigned options $(M=.14, S E=.01$; although none of these features had been associated with either option).

\section{Discussion}

The participants were better able to remember and correctly attribute features of the assigned alternative than of the unassigned alternative. They were, furthermore, more likely to misattribute new features to the unassigned options, suggesting a reliance on metamemory information regarding the quality (familiarity or vividness) of the features. The heuristic influencing source attributions in choice scenarios (Mather et al., 2000), whereby positive features are presumed more likely to have belonged to the chosen option and negative features to the unchosen alternative, evidently plays a lesser role in assignment contexts. Instead, a different heuristic seems to operate: Features that are memorially more vivid are presumed more likely to belong to the assigned option, whereas features that appear more pallid are attributed to the unassigned alternative. This heuristic has the consequence that old features are more likely to be attributed to the assigned option, whereas features are more likely to be attributed to the unassigned alternative.

\section{EXPERIMENT 2}

In Experiment 2, we compared choice and assignment. Participants were presented with hypothetical binarychoice scenarios, each on a separate page of a booklet. Half of the participants were asked to choose an option; the others were assigned an option. After a delay, the participants were given a source attribution test for features of the options.

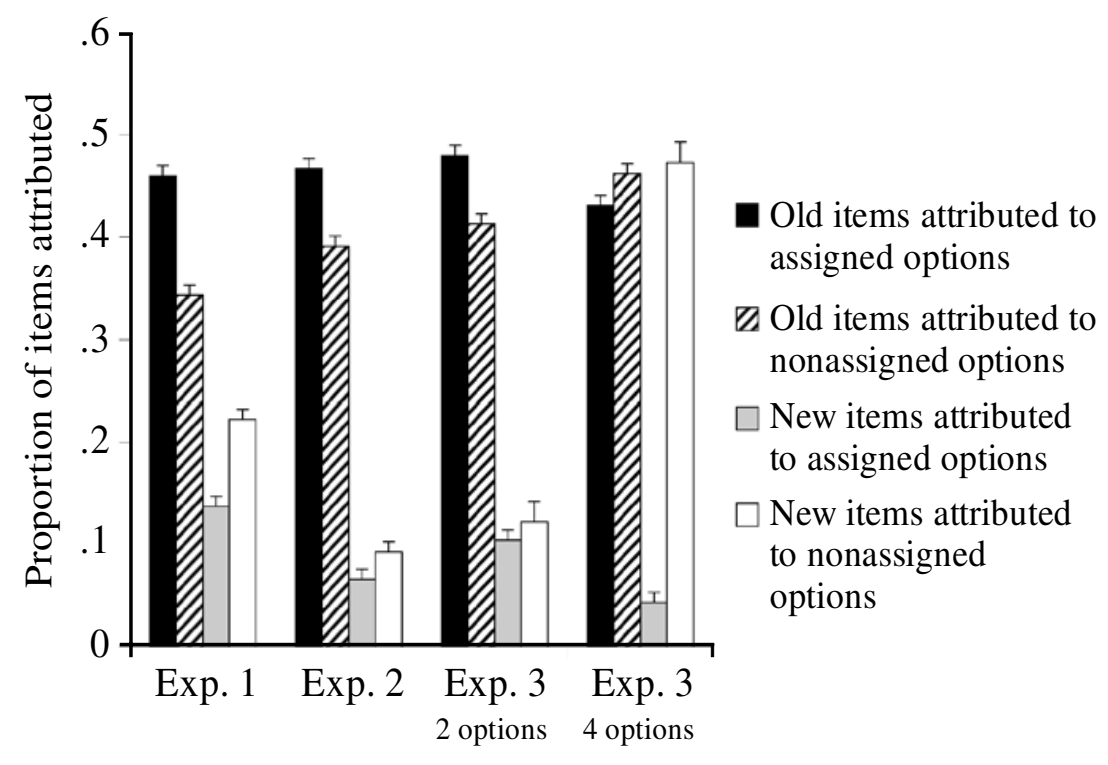

Figure 1. Proportion of all old and new features attributed (both correctly and incorrectly) to assigned and unassigned options in Experiments 1-3. 


\section{Method}

\section{Participants}

The participants were 114 undergraduate volunteers, 49 randomly assigned to the choice condition and 65 to the assignment condition. (The data of 2 additional participants who failed to follow instructions were discarded from all analyses.) Motivated by the fact that participants who misremember which option they chose tend to favor the option they think they chose (rather than the actually chosen option; Mather \& Johnson, 2000), we included data only from participants who correctly identified all their chosen or assigned options. ${ }^{2}$ Twenty participants ( 2 in the choice condition, 18 in the assignment condition) were thereby dropped from further analyses, which happened to leave 47 participants in each condition.

\section{Materials and Procedure}

Three pairs of options-involving houses, roommates, and carswere used for both the choice and the assignment conditions and are reproduced in the Appendix. The participants in the choice condition were asked to choose one option from each pair (e.g., "Please imagine that you are starting a job in a new location and your company owns some properties for their employees to rent at below-market rates. They currently have two houses available. Please circle the house you would choose").

The participants in the assignment condition first received a rating task to ensure that they had read through both options. For example, "Below you will find descriptions of houses. As you read each description, try to decide how much each one is characteristic of a residential neighborhood you know well." Each option in a pair was assigned to approximately half of the participants, who were then asked to rate, on a scale of one to seven, how they felt about it. For example, "Now please imagine that you are starting a job in a new location and your company owns some properties for their employees to rent at below-market rates. They have assigned you the white house built of wood. How much do you think you would like living in it?"

The order of presentation of options within each scenario was counterbalanced, and scenarios appeared in two arbitrary orders. Each option was described by five positive and five negative features (whose valence had been confirmed by independent judges). Overall option valence was not manipulated, as it had proved to have no impact in Experiment 1.

Following the three choices or assignments, the participants completed unrelated questionnaires for about $45 \mathrm{~min}$. They were then given a source memory test for the option features from each scenario. The test was identical for the choice and the assignment conditions, with each scenario tested on a separate page. The memory test included a list of the original (old) features intermingled with positive and negative new features (there were six, eight, and eight new features in the roommate, house, and car scenarios, respectively). The participants were asked to assign each feature to the option to which it originally belonged or to indicate that it was a new feature (i.e., had not been associated with either option). The labels used to identify the options included their order of appearance as well as a descriptive title-for example, "the red brick house (the first one described)" or "the white house made of wood (the second one described)." Upon completion of the source identification memory test, the participants were asked to identify the options they had chosen or had been assigned.

Because the participants in the choice condition would be free to choose either option, it is theoretically possible that a salient option would be chosen more often and remembered more positively (whether or not it was chosen) by a majority of the participants. In such a case, simple averages would suggest that memory attributions would favor the chosen option even though the option was favored independently of being chosen. To avoid such spurious results, a normalized asymmetry score was computed, as described in Mather et al. (2000). This score measures the extent to which a participant's memory attributions favor the chosen option more than it is favored on average. Even an option that was heavily favored, but no more by those who chose it than by those who did not, would receive an asymmetry score of zero, indicating no choice-supportive bias. If, on the other hand, participants tended to make choice-supportive memory attributions, the average asymmetry score would be positive, and if memory attributions tended to favor unchosen alternatives, the average score would be negative. ${ }^{3}$

Because in the assignment condition, unlike in the choice condition, options and participants were randomly matched, this more intricate computation of asymmetry scores was not needed. Thus, in Experiment 1, we simply compared the proportion of old and new items attributed to assigned and unassigned options. In any case, the same pattern of results would be obtained under either measure. For purposes of comparability with the choice data, the assignment data in the present experiment were analyzed using asymmetry scores, along lines similar to those for the choice data (Figure 2). They were then reanalyzed in the same manner as the assignment data of Experiments 1 and 3 (which included only assignments) for comparison with those data.

\section{Results}

In what follows, we will compare assignment and choice participants' old-new recognition accuracy for features and will gauge the extent to which their source attributions favored the assigned or the chosen option. We then will focus on assignment participants' memory for assigned versus unassigned alternatives.

\section{Old-New Recognition}

Each participant's $A^{\prime}$ scores were calculated separately for positive and for negative features in both the choice and the assignment conditions. As in Experiment 1, a 2 (condition: choice or assignment) $\times 2$ (feature valence: positive or negative) ANOVA revealed better recognition of negative features $(M=.90, S E=.01)$ than of positive features $\left[M=.82, S E=.01 ; F(1,92)=78.43, M S_{\mathrm{e}}=0.00\right.$, $p<.001]$. There were no other significant effects, suggesting comparable old-new recognition accuracy following choice versus assignment. Furthermore, there was no significant interaction of condition and feature valence $[F(1,92)=1.46, p=.23]$, indicating that the participants were no more likely to recognize negative features in assigned options than in chosen options.

\section{Choice- Versus Assignment-Supportive Source Monitoring}

Asymmetry scores. Because the scenarios (roommates, houses, and cars) did not yield interactions of interest, these do not figure as a factor in the subsequent analyses. Mean asymmetry scores were analyzed using a 2 (condition: choice or assignment) $\times 2$ (feature valence: positive or negative) $\times 3$ (attribution type: correct, misattribution old feature, or misattribution new feature) ANOVA and are shown in Figure 2. Memory attributions were more supportive of the selected option among those who chose an option $(M=.10, S E=.04)$ than among those who were assigned one $(M=-.07, S E=.04)$, as was indicated by a main effect of condition $[F(1,92)=7.69$, $\left.M S_{\mathrm{e}}=0.53, p<.01\right]$. 


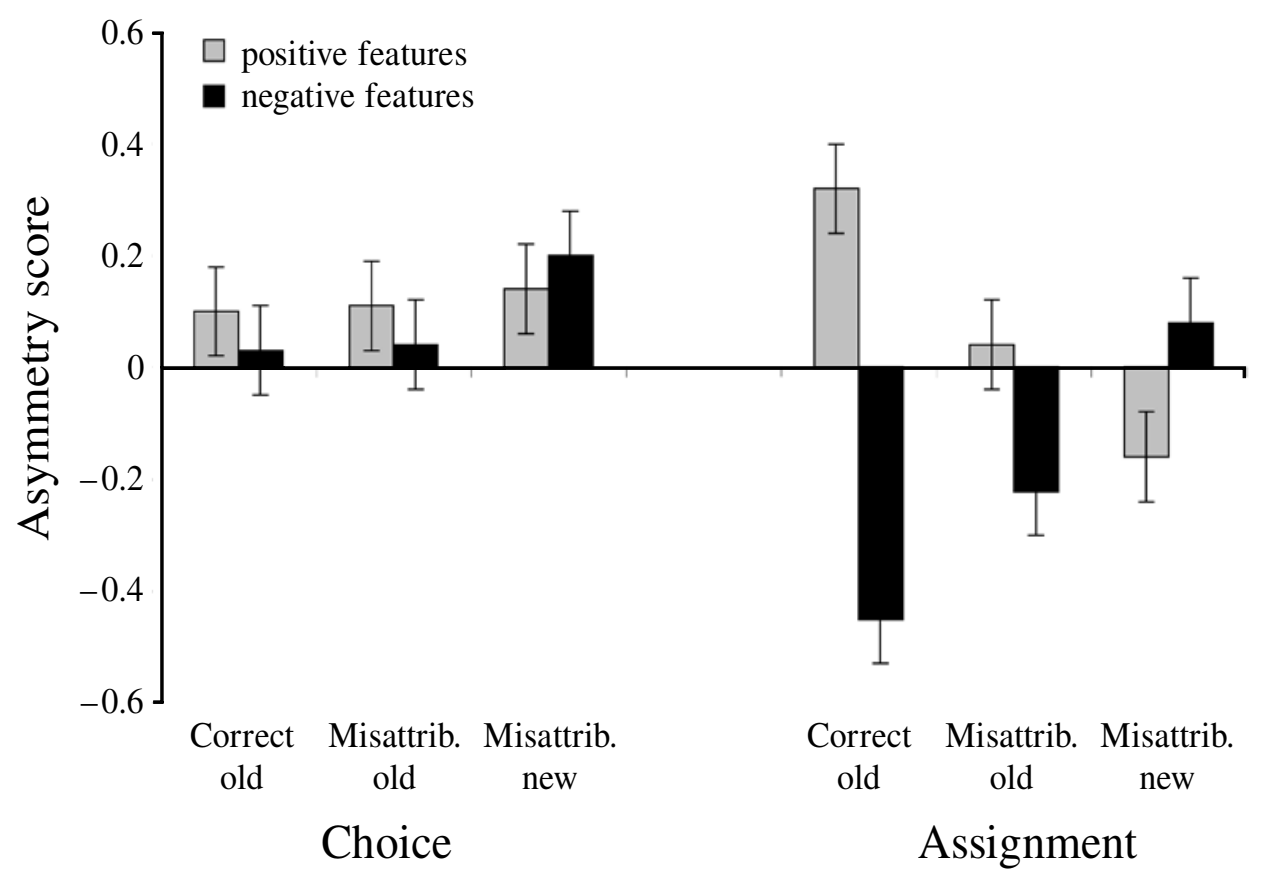

Figure 2. Asymmetry scores for those participants who correctly remembered their choices or assignments in Experiment 2.

As is clear from Figure 2 and from a three-way interaction of condition, valence, and attribution type $[F(2,184)=$ 9.32, $\left.M S_{\mathrm{e}}=0.25, p<.001\right]$, the pattern of asymmetry scores was different for choice and for assignment participants. We thus conducted 2 (feature valence: positive or negative) $\times 3$ (attribution type: correct, misattribution old feature, or misattribution new feature) ANOVAs separately for the choice and the assignment groups. For choice participants, there were no significant effects. Their mean asymmetry score $(M=.10, S E=.05)$, however, was significantly greater than zero $[t(46)=2.13$, $p<.05]$. Thus, across feature types, attributionstended to favor the chosen option, replicating earlier findings of choice-supportive memory (Mather \& Johnson, 2000; Mather et al., 2000).

In contrast, the mean asymmetry score in the assignment condition was negative $(M=-.07, S E=.04)$, although not significantly different from zero $[t(46)=$ $-1.78, p=.08$ ]. Furthermore, assignment participants showed a significant effect of feature valence $[F(1,46)=$ 9.11, $\left.M S_{\mathrm{e}}=0.53, p<.01\right]$, qualified by an interaction with attribution type $\left[F(2,92)=24.36, M S_{\mathrm{e}}=0.25, p<\right.$ $.001]$. Looking at asymmetry scores for correct attributions of old items in the assignment condition (Figure 2), we see a positive average asymmetry score for positive features (highest gray bar), due to greater correct attributions of positive features to assigned options than to their competitors. These same participants, however, also correctly attributed a greater number of negative features to the assigned options, which yielded negative asymmetry scores (lowest black bar). On average, correct attributions were not supportive of the assigned alternative. Instead, they suggest selective memory, with a greater number of correct attributions of positive and negative features made to assigned options than to unassigned options.

\section{Attributions to Assigned and to Unassigned Options}

An examination of the misattribution of old items (Figure 2) suggests that the above pattern of correct attributions in the assignment condition was due to more than just selective memory. In fact, the participants were more likely to attribute negative old features to the assigned option than to its competitoreven when the features were not originally associated with the assigned option. And in a final twist, the pattern was the reverse for new features: The participants were more likely to attribute new features to the unassigned option than to the assigned option. In sum, if a feature had been seen before (positive or negative; associated with either option), the participants were more likely to attribute it to the assigned option. In contrast, new features that appeared familiar enough to be erroneously identified as old were more likely to be attributed to the unassigned option.

As in Experiment 1, the participants seemed to expect the features of assigned options to be associated with better memory than the features of unassigned alternatives. Highly familiar features or those yielding more specific or vivid mental experiences at test were attributed to the assigned option. If a feature appeared vaguely familiar (as 
presumably the misattributed new features did), the participants judged that it had been associated with the unassigned option, the one less carefully scrutinized.

Old-new recognition. To further evaluate the recognition of features, each participant's $A^{\prime}$ scores were computed separately for assigned and for unassigned options. A 2 (source: assigned option or unassigned option) $\times 2$ (feature valence: positive or negative) ANOVA revealed that the participants had somewhat better old-new recognition memory for features belonging to assigned options $(M=.86, S E=.01)$ than for those belonging to unassigned options $\left[M=.84, S E=.01 ; F(1,46)=14.14, M S_{\mathrm{e}}=\right.$ $0.00, p<.001]$. The participants also showed better recognition memory for negative features $(M=.88, S E=$ $.01)$ than for positive features $[M=.82, S E=.01 ; F(1,46)=$ $\left.50.22, M S_{\mathrm{e}}=0.00, p<.001\right]$.

Source attribution accuracy for assigned versus unassigned options. As in Experiment 1, there was a greater number of correct source attributions to assigned options $(M=.90, S E=.01)$ than to unassigned options $\left[M=.84, S E=.01 ; F(1,46)=15.29, M S_{\mathrm{e}}=0.01, p<\right.$ $.001]$. Feature valence did not affect attribution patterns.

Attributions to assigned versus unassigned options. As was previously described for asymmetry scores, different attribution patterns were observed for old and new features of assigned versus unassigned alternatives. A comparison of the raw proportions of old and new features attributed to assigned versus unassigned options, using a 2 (item type: old or new) $\times 2$ (attribution: assigned or unassigned) $\times 2$ (feature valence: positive or negative) ANOVA, revealed the same pattern as that observed earlier. Indeed, as can be seen in Figure 1, there was a significant interaction of item type and attribution $[F(1,46)=$ $\left.30.90, M S_{\mathrm{e}}=0.01, p<.001\right]$. Consistent with a vividness heuristic, the participants were more likely to attribute old features to assigned options $(M=.47, S E=.01)$ than to unassigned options ( $M=.39, S E=.01)$ but were less likely to attribute new features to assigned options than to unassigned options $(M=.07, S E=.01$, and $M=.09$, $S E=.01$, respectively). These patterns replicate Experiment 1 and are consistent with the proposed memory vividness differential between old and new features. They are not consistent with a general tendency for memory to be supportive of the assigned option.

In contrast with the pattern observed in the context of choice, feature valence did not interact with attribution in a manner supportive of the assigned option. In fact, the participants attributed a higher proportion of negative features to assigned options than to unassigned options $(M=$ $.27, S E=.01$, and $M=.22, S E=.01$, respectively), whereas their attributions of positive features did not differ, yielding a significant interaction $\left[F(1,46)=4.73, M S_{\mathrm{e}}=0.01\right.$, $p<.05]$ that disfavored assigned options. Unlike for choice, no tendencies supportive of the selected options were observed following assignment.

\section{Discussion}

People appear to exhibit different types of memory distortion for options they were assigned than for options they chose. When making memory attributions regarding chosen versus unchosen options, people apparently are guided by an implicit, and quite reasonable, assumption that their chosen option is more likely than its competitors to possess the features they find positive and less likely to possess the features they find negative. This assumption, on the other hand, appears to play a lesser role when attributions about assigned versus unassigned options are made. Following assignment, participants appear to rely on the quality of feature memories as a cue. When the phenomenal experience of remembering lacks the qualities of a vivid memory or is only vaguely familiar, as is typically the case with new features, the feature is more likely to be attributed to the unassigned option; conversely, vivid memory experiences, typical of old features, are excessively likely to be attributed to the assigned option.

In fact, the participants were slightly more likely to correctly recognize features belonging to assigned than to unassigned alternatives. This most likely reflects greater attention paid to the features of assigned options. Insofar as more information is encoded about assigned options than about unassigned options, the proclivity to rely on the amount of information activated at test may indeed serve as a useful, albeit imperfect, heuristic when source attributions are made.

After making a choice, people's attributions appear to be guided in part by a simple heuristic according to which attractive features are more likely to belong to the chosen option, whereas unattractive features are more likely to belong to the unchosen alternative. This heuristic should be particularly likely to emerge when memorial characteristics other than valence provide little information about source. In the case of assignment, however, the attractiveness of features provides weaker inferential grounds. Instead, a different heuristic operates: Features that appear vivid are presumed to be more likely to belong to the option assigned, whereas features that appear pallid are more likely to be attributed to the unassigned alternative. As is the nature of heuristics, these may serve a useful role but will yield predictable patterns of error.

\section{EXPERIMENT 3}

In Experiments 1 and 2, we examined memory for scenarios involving binary assignment. In everyday life, however, assignments are often made from within a larger set, and this may further influence memory biases. The presence of more options is likely to reduce memory accuracy overall and, in particular, may render unassigned alternatives even less memorable, relative to the assigned option. A heuristic that suggests attributing pallid features to unassigned alternatives may lead to even greater bias when memory is weaker and the array of unassigned options greater.

One half of the participants in Experiment 3 were presented with a scenario involving two restaurants (call these A and B); the other half were presented with an expanded scenario involving the same two plus two additional restaurants (C and $\mathrm{D})$. In both the two-option and the four-option conditions, half the participants were as- 
signed Restaurant A, and the others were assigned Restaurant B. Note that those in the two-option condition encountered one unassigned alternative, whereas those in the four-option condition encountered three. All the participants received the same memory test, consisting of old features from Restaurants A and B and new features that had not been associated with any restaurant. The hypothesis was that the presence of more options would increase the memory vividness differential between assigned and unassigned options and, thus, increase the tendency to attribute new features to the unassigned alternatives.

\section{Method}

\section{Participants}

One hundred and ten and 105 undergraduate volunteers were randomly assigned to the two-option and the four-option conditions, respectively. One other participant was excluded for leaving most of the memory items blank. Within each condition, about half were assigned to Restaurant A and half to Restaurant B.

\section{Materials and Procedure}

The material for the experiment formed part of a larger packet of questionnaires. The instructions on the first page (the assignment page) for the experiment read as follows:

We are interested in how people evaluate options. Below you will find descriptions of two [four] restaurants in or near Princeton (the descriptions consist of information given in restaurant reviews). Because we would like people to take this task seriously, we will be conducting a drawing to award an actual gift certificate for a meal at each restaurant at the end of the semester.

Following the instructions were descriptions of the two or four unnamed restaurants. Each description consisted of positive features (e.g., "gourmet dishes," "friendly service") and negative features (e.g., "some dishes are bland," "long wait"). The assigned restaurant was indicated below the descriptions. (Both restaurant assignment and order of mention were counterbalanced.) The participants were asked to review all the alternatives, to write a brief description of how they felt about their assigned restaurant, and to rate (on a 7point scale) their anticipated satisfaction with it. The participants then filled out their contact information for purposes of the drawing. (Following the experiment, a meal at each restaurant was awarded.)

After approximately 45-min work on unrelated tasks, the participants received a source identification test. The test listed restaurant features, and the participants were instructed to indicate, for each feature, whether it was associated with the assigned restaurant, was associated with one of the unassigned restaurants, or had not been part of any of the restaurant descriptions. The test included, in random order, all 14 features from Restaurants A and B (i.e., old features), along with 4 negative and 4 positive features not seen before (i.e., new features).

\section{Results and Discussion}

\section{Old-New Recognition}

As was expected, a 2 (version: two-options or fouroptions) $\times 2$ (feature valence: positive or negative) $\times 2$ (source: assigned or unassigned) ANOVA of $A^{\prime}$ scores revealed better memory for features in the two-option condition $(M=.86, S E=.01)$ than for those in the fouroption condition $[M=.74, S E=.01 ; F(1,213)=75.87$, $\left.M S_{\mathrm{e}}=0.03, p<.001\right]$. As before, the participants were slightly more likely to correctly recognize features belonging to their assigned option $(M=.81, S E=.01)$ than those belonging to other options $[M=.79, S E=.01$;
$\left.F(1,213)=5.91, M S_{\mathrm{e}}=0.00, p<.05\right]$. Version and source did not significantly interact $(p>.3)$, indicating that the old-new recognition accuracy advantage of assigned over unassigned options was not significantly greater in the four-option condition $(M=.75, S E=.01$ vs. $M=.73, S E=.01)$ than in the two-option condition $(M=.86, S E=.01$ vs. $M=.85, S E=.01)$. As in the preceding experiments, the participants had more accurate old-new recognition for negative features $(M=.84, S E=$ $.01)$ than for positive features $[M=.76, S E=.01$; $\left.F(1,213)=63.42, M S_{\mathrm{e}}=0.02, p<.001\right]$.

\section{Source Attribution Accuracy for Assigned Versus Unassigned Options}

Unlike in the previous two experiments, there was not a significantly greater number of correct attributions to the assigned option. However, there was an interaction of version and source $\left[F(1,209)=24.76, M S_{\mathrm{e}}=0.03, p<\right.$ $.001]$. In the two-option condition, as in the previous experiments, correct attributions were more likely for the assigned options $(M=.92, S E=.01)$ than for the unassigned options $(M=.88, S E=.02)$. In contrast, in the fouroption condition, correct attributions were less likely for the assigned option $(M=.82, S E=.01)$ than for the unassigned options $(M=.90, S E=.02)$. The following analyses suggest that this increased source accuracy for unassigned options was most likely due to attributional bias, rather than to improved memory.

\section{Attributions to Assigned Versus Unassigned Options}

A 2 (version: two-options or four-options) $\times 2$ (item type: old or new) $\times 2$ (attribution: assigned or unassigned) $\times 2$ (feature valence: positive or negative) ANOVA revealed a significant interaction of item type and attribution $\left[F(1,213)=183.17, M S_{\mathrm{e}}=0.03, p<.001\right]$. As in the previous two experiments, the participants were more likely to attribute old features to assigned options $(M=$ $.46, S E=.01)$ than to unassigned options $(M=.44, S E=$ $.01)$ but were more likely to attribute new features to unassigned options $(M=.30, S E=.01)$ than to assigned options $(M=.07, S E=.01)$.

This effect was qualified by a three-way interaction of item type, attribution, and version $[F(1,213)=79.17$, $\left.M S_{\mathrm{e}}=0.03, p<.001\right]$. As can be seen in Figure 1, the pattern in the two-option condition replicated Experiments 1 and 2 , with a significant item type $\times$ attribution interaction $\left[F(1,109)=15.41, M S_{\mathrm{e}}=0.02, p<.001\right]$. This interaction, however, was more extreme in the four-option condition $\left[F(1,104)=189.21, M S_{\mathrm{e}}=0.04, p<.001\right]$ than in any of the experiments' two-option conditions. As can be seen in the right-hand section of Figure 1, participants attributed a greater number of new features than old features to the unassigned options. The four-option context did not merely increase attributions to unassigned options; it did so more for new than for old features. This is consistent with the notion that the four-option context yielded poorer memory, particularly for the unassigned alternatives. The presence of more options increased attri- 
bution of old features to unassigned alternatives, probably because fewer features now appeared familiar or vivid enough to be associated with the option assigned. ${ }^{4}$ The presence of more options, however, had the greatest impact on the attribution of new features, which, to the extent that they felt mildly familiar, seemed more likely to belong to one of a number of vaguely remembered unassigned alternatives than to the assigned and more vividly remembered option.

A valence $\times$ attribution interaction $[F(1,213)=32.44$, $\left.M S_{\mathrm{e}}=0.04, p<.001\right]$ indicated that positive features were more frequently attributed to unassigned options than to assigned options $(M=.41, S E=.01$, vs. $M=.25$, $S E=.01$, respectively), whereas negative features were attributed more to assigned options than to unassigned options $(M=.33, S E=.01$, vs. $M=.28, S E=.01$, respectively). This pattern, unsupportive of the assigned option, is likely attributable to the fact that positive features tended to be remembered less well than negative features and, thus, did not seem vivid enough to have belonged to the assigned option.

Experiment 3 replicated the results of the preceding two experiments, again revealing a tendency to misattribute new features to unassigned options rather than to assigned options. The experiment further demonstrated that an increasing number of unassigned options reduced the participants' old-new recognition ability and, thus, exacerbated the attribution of new features to these options.

\section{GENERAL DISCUSSION}

When recollecting past decisions, people are more likely to attribute positive features to the options they chose and negative features to the unchosen options (Mather \& Johnson, 2000; Mather et al., 2000). This source-monitoring bias in support of the selected option was replicated in Experiment 2 but was not observed when options were assigned, rather than chosen, in three separate experiments. Assigned options were remembered no more positively than unassigned alternatives, which suggests that choice-supportive memory biases are unlikely to be due merely to the motivation to believe that the option in one's possession is superior. Instead, choicesupportive biases are attributable to people's quite reasonable beliefs regarding the greater attractiveness of the chosen option over the unchosen alternatives.

This notwithstanding, systematic bias was also observed following assignment. Like their counterparts who had made choices, assignment participants' attributions were influenced by a simple heuristic. Unlike choice participants, however, their heuristic was based on familiarity or vividness, rather than on valence. Features-positive or negative - that appeared vaguely familiar but insufficiently familiar or vivid were deemed more likely to belong to unassigned options, whereas more familiar or vivid features were assumed to belong to the assigned alternative. This was true both for positive and for negative features (Experiments 1-3) and increased as option recognition diminished (Experiment 3 ).
Features' affective quality influenced overall old-new recognition accuracy. In all three experiments, in both choice and assignment, the participants' old-new recognition was more accurate for negative features than for positive features. This recognition asymmetry replicates previous studies of memory for choices (Mather \& Johnson, 2000; Mather et al., 2000). Negative information dominates positive information in a variety of contexts (for reviews, see Baumeister, Bratslavsky, Fickenauer, \& Vohs, 2001; Rozin \& Royzman, 2001). Potential losses loom larger than gains in decision making (e.g., Tversky \& Kahneman, 1991), and negative characteristics have greater impact than do positive characteristics in evaluation (e.g., Kanouse \& Hanson, 1972). The difference in salience of positive and negative features is likely to have contributed to the better old-new recognition memory for negative features than for positive features observed in our experiments.

According to the source-monitoring framework (Johnson et al., 1993; Johnson \& Raye, 2000; Mitchell \& Johnson, 2000), the attribution of memory to a source depends on people's knowledge and expectations regarding the qualities of memories from various sources. That is, people make use of various characteristics of memories (such as perceptual, contextual, and affective information, semantic detail, and cognitive operations) when attributing those memories to their supposed sources. Certain qualitative characteristics can, in fact, prove quite useful in determining the source of activated information. For example, memories of imagined events tend to be associated with a greater number of cognitive operations than are memories of perceived events, which in turn tend to be associated with greater perceptual detail. Thus, a memory associated with vivid cognitive operations is most likely to have been imagined, whereas a memory rich in perceptual detail is most likely to have been perceived. Our studies show that feature valence influences source monitoring in people's memories of choices they made, whereas feature familiarity or vividness influences source monitoring in people's memories of choices made for them.

Our finding of different patterns of attribution biases for choices and assignments reveals that people have different beliefs about what qualities are most likely to be associated with options in the two situations. Our findings of distinct attribution patterns for choices versus assignments suggest that people have different expectations regarding the qualities most likely to be salient in the two cases. After considering two options and making a choice themselves, people believe that their selected option is better than the other option. Having made a choice themselves, people quite reasonably expect their chosen option to be more attractive than the alternatives. In contrast, they do not hold such expectations with regard to options assigned to them. Again quite reasonably, people do not believe that the option randomly assigned to them is any better than the other option.

Benney and Henkel (2002) recently replicated this effect, finding supportive memory attributions in the context of choice, but not of assignment. In addition to a 
choice and an assignment condition, they also included a third condition in which a computer presumably assigned participants the option it had determined, on the basis of responses to a personality test, that they would like best (although in reality the assignments were random). In this best-interest condition, the participants' memory attributions were as choice supportive as those in the original choice condition. This provides additional evidence that people's expectations about options play a key role in guiding their memory attributions.

In contrast with choice, attributions in our assignment condition were influenced by expectations regarding the familiarity or vividness of remembered features. Having encountered a larger number of options (as in Experiment 3 ), the participants evidently lowered their vividness threshold for attributing new features to unassigned alternatives. In fact, whereas only $12 \%$ of the new features were attributed to unassigned options in the two-option condition, this rose to nearly $50 \%$ in the four-option condition. In general, attribution criteria shift on the basis of people's expectations of how vividly they ought to remember relevant items. For example, people are less likely to falsely recognize associated words if their original encounter with the words included related pictures (Schacter, Israel, \& Racine, 1999), thus raising the amount of detail they expect to have encoded (see also Brown, Buchanan, $\&$ Cabeza, 2000).

Of course, the absence of certain qualitative information can also act as a cue for source (e.g., Marsh \& Hicks, 1998), as was highlighted in our study by the tendency to attribute new features - typically, lacking in vivid detailto the unassigned options. The amount of various qualitative characteristics has been shown to lead to attribution biases in other contexts as well. For example, people are more likely to misidentify as famous names that had previously been presented, as compared with new names, because they expect famous names to appear more familiar (e.g., Jacoby, Kelley, Brown, \& Jasechko, 1989). Participants asked to identify various items as self-generated, experimenter presented, or new were more likely to misattribute new items to the experimenter than to themselves (Johnson et al., 1981). Thus, items that seemed mildly familiar but carried no more specific source memory characteristics tended to be attributed to external sources (see also Marsh \& Bower, 1993). This "it-had-to-be-you" effect is reminiscent of the "it-had-to-be-the-other-option" effect observed in the present assignment conditions. Source-monitoring heuristics have been demonstrated in a variety of other contexts-for example, when people's stereotyped beliefs about potential memory sources influence their attributions (e.g., Bayen et al., 2000; Mather et al., 1999; Sherman \& Bessenoff, 1999). Thus, participants are more likely to misattribute a previously heard statement, "I'm pro-choice," to a Democrat than to a Republican (Mather et al., 1999).

Our findings raise some interesting questions for future studies to address. The "it-had-to-be-the-other-option" effect seen in our assignment conditions was associated with better recognition memory for assigned options than for unassigned options. Presumably, the participants examined more carefully and thought more about assigned options than about unassigned alternatives. We would expect the proclivity to attribute old features to assigned options and new features to unassigned options to disappear in contexts in which people do not expect to remember assigned options better. This might occur, for example, when all the options are highly familiar (yet intricate enough to pose some memory challenges). In a similar fashion, it is possible that the tendency to attribute positive features to the chosen option and negative features to the foregone alternatives might diminish when the choice is remembered as having been hard to make and, consequently, the inference regarding the superiority of the chosen option seems less warranted. These possibilities remain to be tested.

Another issue not addressed by our study is the extent to which source-monitoring heuristics might interact. A feature, for example, might be recalled vividly and also seem highly positive. Would reliance on the vividness heuristic interact with reliance on the valence heuristic in such a case? More generally, how likely are people to rely on more than one heuristic when making memory attributions?

Our experiments mostly involved hypothetical choices and assignments (except for the actual restaurant meals awarded in Experiment 3). Of course, actual behavior may differ in important ways from what is observed in hypothetical contexts. On the other hand, the general cognitive principles people exhibit in their attempt to reconstruct the relevant scenarios in such experiments are likely to provide insights into those that operate in more natural settings.

Prominent in our studies were the heuristics that people employed in making source attribution decisions. Attributions regarding past choice options were partly motivated by evaluative inferences, with positive features considered more likely to have belonged to the chosen option and negative features to the unchosen alternatives. Among other things, this proclivity may contribute to the spreading of alternatives phenomena observed long ago by social psychologists (e.g., Brehm, 1956), in which, following a choice, the decision maker comes to evaluate the chosen option as being more attractive than it was before it had been chosen. Choice-supportive biases may thus be classified as yet another way in which memory can become distorted, thereby rendering our past selves and behaviors more gratifying (e.g., Greenwald, 1980; Ross \& Wilson, 2000).

In contrast, the monitoring of memories for assigned options was influenced primarily by the apparent vividness or familiarity of features, with vivid or highly familiar features more likely to be attributed to the assigned option and less vivid or less familiar features more likely attributed to the unassigned alternatives. As with other common heuristics, these are by no means unreasonable. In the context of choice, there certainly would be expected to be a correlation between the presence of attractive versus unattractive features and the options we chose or did not. Similarly, in assignment contexts, we surely would expect to have better recall for the option assigned than 
for those that were not (as was, in fact, observed in the present experiments). Like other common heuristics, however, these are bound to fail in predictable and systematic ways. After all, not all attractive features come with the option we chose, nor do all memorable features belong to the assigned option.

In the experiment above, we explored some implications from the source-monitoring frameword for the monitoring of options in the context of decisions. Inferential processes guiding memory monitoring were found to differ in systematic and predictable ways when options were assigned, as compared with when they were chosen. Research in decision making has documented various ways in which changes in context and procedure can influence decisions (for a review, see Shafir \& LeBoeuf, 2002). The present work suggests that similar changes can also influence how decisions are remembered.

\section{REFERENCES}

Baumeister, R. F., Bratslavsky, E., Fickenauer, C., \& Vohs, K. D. (2001). Bad is stronger than good. Review of General Psychology, 5, 323-370.

Bayen, U. J., NaKamura, G. V., Dupuis, S. E., \& Yang, C. -L. (2000). The use of schematic knowledge about sources in source monitoring. Memory \& Cognition, 28, 480-500.

Benney, K. E., \& Henkel, L. A. (2002, November). The role of free choice in memory biases for past decisions. Paper presented at the 43rd Annual Meeting of the Psychonomic Society, Kansas City, MO.

Brenm, J. W. (1956). Postdecision changes in the desirability of alternatives. Journal of Abnormal \& Social Psychology, 52, 384-389.

Brown, N. R., Buchanan, L., \& Cabeza, R. (2000). Estimating the frequency of nonevents: The role of recollection failure in false recognition. Psychonomic Bulletin \& Review, 7, 684-691.

Greenwald, A. G. (1980). The totalitarian ego: Fabrication and revision of personal history. American Psychologist, 35, 603-618.

HolyoAK, K. J., \& Simon, D. (1999). Bidirectional reasoning in decision making by constraint satisfaction. Journal of Experimental Psychology: General, 128, 3-31.

Jacoby, L. L., Kelley, C., Brown, J., \& JASechKo, J. (1989). Becoming famous overnight: Limits on the ability to avoid unconscious influences of the past. Journal of Personality \& Social Psychology, 56, 326-338.

Johnson, M. K., Foley, M. A., Suengas, A. G., \& Raye, C. L. (1988). Phenomenal characteristics of memories for perceived and imagined autobiographical events. Journal of Experimental Psychology: General, 117, 371-376.

Johnson, M. K., HASHT Roudi, S., \& LindSAY, D. S. (1993). Source monitoring. Psychological Bulletin, 114, 3-28.

Johnson, M. K., \& RAYE, C. L. (1981). Reality monitoring. Psychological Review, 88, 67-85.

Johnson, M. K., \& RAYE, C. L. (2000). Cognitive and brain mechanisms of false memories and beliefs. In D. L. Schacter \& E. Scarry (Eds.), Memory, brain, and belief (pp. 25-86). Cambridge, MA: Harvard University Press.

Johnson, M. K., Raye, C. L., Foley, H. J., \& Foley, M. A. (1981). Cognitive operations and decision bias in reality monitoring. American Journal of Psychology, 94, 37-64.

JoHnson, M. K., \& SHERMAN, S. J. (1990). Constructing and reconstructing the past and the future in the present. In E. T. Higgins \& R. M. Sorrentino (Eds.), Handbook of motivation and cognition: Foundations of social behavior ( pp. 482-526). New York: Guilford.

Kanouse, D. E., \& Hanson, L. R. J. (1972). Negativity in evaluations. In E. E. Jones, D. E. Kanouse, H. H. Kelley, R. E. Nisbett, S. Valins, \& B. Weiner (Eds.), Attribution: Perceiving the causes of behavior (pp. 47-62). Morristown, NJ: General Learning Press.

KunDA, Z (1990). The case for motivated reasoning. Psychological Bulletin, 108, 480-498.
Macmillan, N. A., \& Creelman, C. D. (1991). Detection theory: A user's guide. New York: Cambridge University Press.

MARsh, R. L., \& Bower, G. H. (1993). Eliciting cryptomnesia: Unconscious plagiarism in a puzzle task. Journal of Experimental Psychology: Learning, Memory, \& Cognition, 19, 673-688.

MARSH, R. L., \& Hicks, J. L. (1998). Test formats change sourcemonitoring decision processes. Journal of Experimental Psychology: Learning, Memory, \& Cognition, 24, 1137-1151.

Mather, M., Henkel, L. A., \& Johnson, M. K. (1997). Evaluating characteristics of false memories: Remember/know judgments and memory characteristics questionnaire compared. Memory \& Cognition, 25, 826-837.

Mather, M., \& Johnson, M. K. (2000). Choice-supportive source monitoring: Do our decisions seem better to us as we age? Psychology \& Aging, 15, 596-606.

Mather, M., Johnson, M. K., \& De Leonardis, D. M. (1999). Stereotype reliance in source monitoring: Age differences and neuropsychological test correlates. Cognitive Neuropsychology, 16, 437-458.

Mather, M., Shafir, E. \& Johnson, M. K. (2000). Misrememberance of options past: Source monitoring and choice. Psychological Science, 11, 132-138.

Mitchell, K. J., \& Johnson, M. K. (2000). Source monitoring: Attributing mental experiences. In E. Tulving \& F. I. M. Craik (Eds.), The Oxford handbook of memory (pp. 179-195). Oxford: Oxford University Press.

Norman, K. A., \& Schacter, D. L. (1997). False recognition in younger and older adults: Exploring the characteristics of illusory memories. Memory \& Cognition, 25, 838-848.

Roediger, H. L., III (1996). Memory illusions. Journal of Memory \& Language, 35, 76-100.

Ross, M. (1989). Relation of implicit theories to the construction of personal histories. Psychological Review, 96, 341-357.

Ross, M., \& WiLson, A. E. (2000). Constructing and appraising past selves. In D. L. Schacter \& E. Scarry (Eds.), Memory, brain, and belief (pp. 231-258). Cambridge, MA: Harvard University Press.

Rozin, P., \& Royzman, E. B. (2001). Negativity bias, negativity dominance, and contagion. Personality \& Social Psychology Review, 5, 296-320.

SCHACTER, D. L. (1999). The seven sins of memory: Insights from psychology and cognitive neuroscience. American Psychologist, 54, 182203.

Schacter, D. L., Israel, L., \& Racine, C. (1999). Suppressing false recognition in younger and older adults: The distinctiveness heuristic. Journal of Memory \& Language, 40, 1-24.

Shafir, E., \& LeBoeuf, R. A. (2002). Rationality. Annual Review of Psychology, 53, 491-517.

Sherman, J. W., \& Bessenoff, G. R. (1999). Stereotypes as source monitoring cues: On the interaction between episodic and semantic memory. Psychological Science, 10, 106-110.

Simon, D., Pham, L. B., Le, Q. A., \& Holyoak, K. J. (2001). The emergence of coherence over the course of decision making. Journal of Experimental Psychology: Learning, Memory, \& Cognition, 27, 1250-1260.

SPANIOL, J., \& BAYEN, U. J. (2002). When is schematic knowledge used in source monitoring? Journal of Experimental Psychology: Learning, Memory, \& Cognition, 28, 631-651.

Suengas, A. G., \& Johnson, M. K. (1988). Qualitative effects of rehearsal on memories for perceived and imagined complex events. Journal of Experimental Psychology: General, 117, 377-389.

Tversky, A., \& Kahneman, D. (1991). Loss aversion in riskless choice: A reference dependent model. Quarterly Journal of Economics, 107, 1039-1061.

\section{NOTES}

1. In this and subsequent analyses of the attribution of old and new features to assigned and unassigned options, we do not discuss those effects that are not of theoretical interest (e.g., main effects indicating that old features were more likely to be attributed to options than were new features).

2. It is interesting to look at the few respondents who occasionally misremembered which option they had been assigned in Experiments 1 and 2 . For their correctly remembered assignments, these people were 
more likely to attribute old items to assigned options than to unassigned options, as is the usual pattern. However, for their misremembered assignments, they were more likely to attribute old items to the purportedly assigned option than to the actually assigned option. Similar to findings in the context of choice, misidentifying an option as the one assigned can apparently trump the truly assigned alternative.

3. The asymmetry score calculations performed for each person on each choice problem are outlined below (for more detail and discussion, see Mather et al., 2000). For correctly attributed positive features, the extent to which the person's memory attributions favored an option (call it Option A) was computed by subtracting the proportion of correctly attributed positive features favoring the competing option (Option B) from those favoring A. The resulting sums were then converted to $z$ scores such that the mean value across all participants was zero. Relative to the mean, a positive value indicates that the person's attributions favored Option A, whereas a negative value indicates favoring of Option B. (This measure may actually underestimate the extent of bias when one option is overwhelmingly preferred. Our choice group, however, exhibited no more than a $20 \%$ difference in popularity between options.) This score was left intact for those who chose Option A (thus capturing the extent to which they favored their chosen option), whereas for people who chose Option B, the score was multiplied by -1 . This formula was repeated for positive misattributed old features and for positive new features, and similar calculations (for correct attributions, misattributions of old features, and misattributions of new features) were then repeated for negative features. Finally, the scores for all feature types were combined to yield a general measure of the extent to which memory attribution favored the chosen option over its alternative.

4. Although all test items were kept the same in the two- and fouroption conditions, simple base rate considerations may have motivated some participants to attribute more features to the (more plentiful) unassigned options in the latter condition. The differential attribution of new versus old features, however, suggests influences other than mere base rate considerations.

\section{APPENDIX}

Choice Scenarios With Positive and Negative Features (Valence Was Not Indicated for Participants)

\section{Room A}

near the center of campus $(+)$

new furniture $(+)$

large closet $(+)$

newly renovated $(+)$

bathroom far from room $(-)$

large windows $(+)$

laundry room conveniently located $(+)$

chilly in the winter $(-)$

dark hallway leading to room (-)

sunny room $(+)$

\section{Student A}

careful $(+) \ldots$ moody $(-) \ldots$ motivated $(+) \ldots$ thorough $(+) \ldots$ often late to class $(-) \ldots$ gets good grades $(+) \ldots$ lives near you $(+) \ldots$ bad at math $(-)$

\section{Red brick house}

Beautiful architectural details (+)

Cathedral ceilings $(+)$

No basement $(-)$

Within walking distance to stores $(+)$

Newly renovated and fully-equipped kitchen

Small bedrooms $(-)$

Driveway is shared with neighbors (-)

Plenty of electrical outlets in each room $(+)$

Cracks in the walls (-)

Only one bathroom (-)

\section{Room B}

has air conditioning $(+)$

some of your friends live in that dorm $(+)$

somewhat noisy $(-)$

concrete floor $(-)$

has a vaulted ceiling and skylight $(+)$

nice view $(+)$

walls need to be painted $(-)$

nice lounge down the hall $(+)$

room has good lighting $(+)$

bathroom only shared with one person $(+)$

\section{Student B}

good writer $(+) \ldots$ interrupts people sometimes $(-)$... easily discouraged $(-)$... pleasant voice $(+) \ldots$ intelligent $(+) \ldots$ good sense of humor $(+) \ldots$ often seems nervous $(-)$... helpful $(+)$

\section{White house built of wood}

Lots of sunlight $(+)$

Beautifully landscaped yard $(+)$

No garage (-)

Quite spacious (+)

Poor insulation (-)

Safe neighborhood $(+)$

Has an old oil furnace $(-)$

Floor visibly uneven in some places (-)

Water stains on the ceiling on the top

floor (-)

Newly refinished wood floors $(+)$ 


\section{APPENDIX (Continued)}

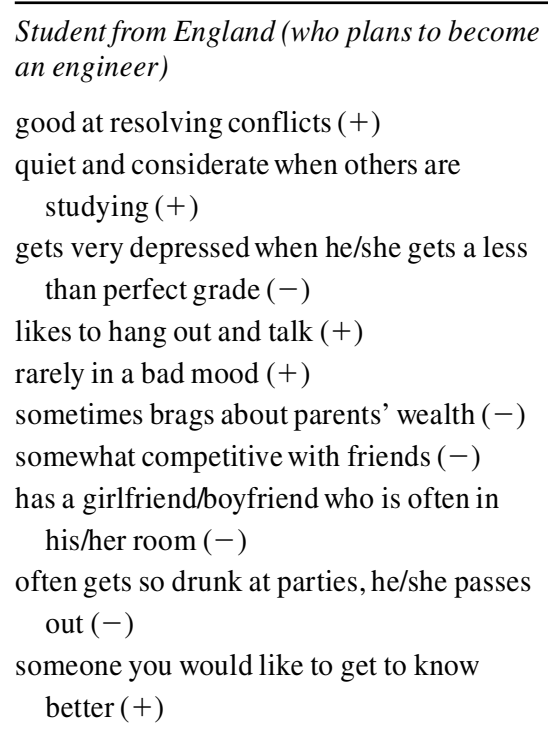

Black Car

No warranty (-)

Some rust on exterior $(-)$

High resale value $(+)$

Has airbags $(+)$

Needs a few repairs $(-)$

Not much trunk space $(-)$

Powerful engine (+)

Previous owner took good care of car $(+)$

Not fuel efficient $(-)$

Has a sun roof $(+)$

\section{Restaurant A}

Gourmet dishes $(+)$... Slow service $(-)$... Nice view (+) ... Said to be overrated (-) ... Nice, light meals $(+)$... Some dishes are bland $(-)$... Extraordinary architecture (+)

\section{Restaurant $C$}

Friendly service (+) ...Poor lighting (-) ... Tasty appetizers $(+)$... Tends to get mediocre ratings in reviews $(-)$...

Meticulously prepared fare (+) ... Varied and interesting dishes (+)
Student from California (who plans to become a journalist)

has a car he/she is happy to lend to others (+)

likes to include friends in his/her activities (+)

has poor table manners $(-)$

often has long phone conversations (-)

has many interests $(+)$

happy to share his/her music CD's $(+)$

easily annoyed (-)

leaves dirty laundry piled around the room (-)

would never use someone else's things without permission $(+)$

often mentions that he/she was valedictorian in high school (-)

\section{Red Car}

Hard to find service outlets (-)

Has dent from a previous accident $(-)$

Seats are very comfortable $(+)$

Good handling on turns $(+)$

High mileage on odometer (-)

Makes an unidentified rattling sound (-)

Prestigious model (+)

Air conditioning included $(+)$

Doesn't do well in bad weather $(-)$

Stereo included $(+)$

\section{Restaurant $B$}

Attentive staff $(+)$... Long wait for tables

$(-)$... Imaginative menu (+) ... Noisy (-) ...

Fresh ingredients $(+) \ldots$ Quality has

declined recently (-) ... Delicious drinks (+)

\section{Restaurant $D$}

Diverse selection $(+) \ldots$ One expects more at these prices $(-)$... Hip bar $(+)$... Uneven food quality (-) ... Tasteful, attractive setting $(+)$... Food is nothing new $(-)$... Convenient location $(+)$ 